\title{
Ploidy Levels and Pollen Stainability of Lantana camara Cultivars and Breeding Lines
}

\author{
David M. Czarnecki II \\ University of Florida, IFAS, Department of Environmental Horticulture, \\ Gulf Coast Research and Education Center, 14625 County Road 672, \\ Wimauma, FL 33598
}

Amanda J. Hershberger and Carol D. Robacker
University of Georgia, Department of Horticulture, GA Station, 1109
Experiment Street, Griffin, GA 30223

David G. Clark

University of Florida, IFAS, Department of Environmental Horticulture, Gainesville, FL 32622

\author{
Zhanao Deng ${ }^{1}$ \\ University of Florida, IFAS, Department of Environmental Horticulture, \\ Gulf Coast Research and Education Center, 14625 County Road 672, \\ Wimauma, FL 33598
}

Additional index words. invasive potential, invasive species, male sterility, meiotic abnormality, polyploid, tetraploid, triploid

\begin{abstract}
Lantana camara L., a popular nursery and landscape plant, is categorized as an invasive species in Florida, because it produces viable pollen and cross-pollinates with the native species Lantana depressa Small. The invasive potential of $L$. camara is a challenging issue for the nursery and landscape industry, so sterile non-invasive cultivars are needed to replace fertile invasive ones. This study aimed to determine the ploidy level and male fertility of both commercial $L$. camara cultivars and breeding lines to identify male-sterile cultivars and assess the effectiveness of sterile triploid production in L. camara. A polyploid series was identified among $32 \mathrm{~L}$. camara cultivars and breeding lines. Male fertility, based on pollen stainability, varied widely among the cultivars/breeding lines. Ploidy level was the most important factor determining $L$. camara pollen stainability/male sterility. On average, diploids exhibited the highest pollen stainability $(64.6 \%)$ followed by tetraploids $(45.1 \%)$, pentaploids $(34.6 \%)$, and hexaploids $(18.0 \%)$. Triploids showed the lowest pollen stainability $(\mathbf{9 . 3} \%)$, suggesting that generating triploids would be an effective genetic approach to producing sterile $L$. camara and reducing its pollen-mediated invasiveness. Pollen stainability of triploid cultivars, Balandpawn (Landmark ${ }^{\mathrm{TM}}$ Pink Dawn PP15,516), Lemon Drop, Miss Huff, New Gold, New Red Lantana, Red Butler, Red Spread Lantana, Samson Lantana, and Sunset Lantana was consistently below $10 \%$. A number of triploid cultivars had pollen stainability approaching $20 \%$ to $30 \%$, indicating a necessity for careful examination and screening of newly produced triploids to ensure high sterility in selected triploids. Pollen stainability variation was observed within ploidy levels, implying the existence of other genetic and environmental factors that influence the pollen stainability/male fertility of $L$. camara. Results from this study suggest that there is excellent potential to develop genetically sterile cultivars in $L$. camara for the U.S. nursery and landscape industry.
\end{abstract}

\footnotetext{
Received for publication 12 Aug. 2014. Accepted for publication 8 Sept. 2014.

This project was funded in part by the Florida Nursery Growers and Landscape Association (FNGLA), the Southwest Florida Water Management District, the USDA/CSREES/TSTAR (U.S. Department of Agriculture/Cooperative States Research, Extension and Education Service/Tropical and Subtropical Agriculture) program, and USDA/CSREES Floriculture and Nursery Research Initiative.

We thank Charles Barrett, Joyce Jones, Gail Bowman, and Sarah Smith for their technical assistance.

${ }^{1}$ To whom reprint requests should be addressed; e-mail zdeng@ufl.edu.
}

Lantana camara L. (Verbenaceae) is often grown as a container plant, groundcover, or accent plant. It is valued for its ability to produce bright flowers, attract numerous species of butterflies, and tolerate harsh environ(Arnold, 2002; Schoellhorn, 2004). Lantana has been a major component of the U.S. nursery industry for decades because it is easy to propagate and has short production cycles. (Arnold, 2002; Schoellhorn, 2004). A 2009 survey of the Florida nursery industry indicated that $19 \%$ of responding Florida growers produced lantana, generating an estimated annual sales value of over $\$ 40$ million, mental conditions with little maintenance which accounted for over $1 \%$ of Florida's total nursery industry plant sales (Wirth et al., 2004).

Lantana camara originated in the Western Indies (Sanders, 2001) and was introduced by European explorers to almost all tropical regions by 1900 (Howard, 1969). Since then, it has escaped cultivation and become naturalized through most of the tropical and sub-tropical world (Sanders, 2006). In the United States, L. camara is found in 14 contiguous states from North Carolina to California as well as Hawaii, Puerto Rico, and the Virgin Islands (U.S. Department of Agriculture/National Resources Conservation Service, 2011). In Florida, escaped L. camara plants have hybridized with a Florida native lantana species, Lantana depressa Small. Sanders (1987a) recorded natural interspecific hybrids between $L$. camara and L. depressa, including its all three varieties, var. depressa, var. sanibelensis R.W. Sanders, and var. floridana (Moldenke) R.W Sanders, at 60 locations in Florida. Presumably, such hybridization was facilitated by various insect pollinators, including butterflies and bees, which visit lantana flowers (Dehgan, 2006; Mathur and Ram, 1986; Schemske, 1976). Such interspecific hybridization has resulted in genetic contamination of the native species (Hammer, 2004) and has driven $L$. depressa to endangered status (Weaver and Anderson, 2010). The Florida Exotic Pest Plant Council (FLEPPC) began to list $L$. camara as a Category I invasive plant in 2001 (FLEPPC, 2001). Subsequently, the University of Florida's Institute of Food and Agricultural Sciences (UF/IFAS) Assessment of Non-Native Plants in Florida's Natural Areas recommended "No Use" of L. camara in south and central Florida and "Caution" in using L. camara in north Florida (IFAS Invasive Plant Working Group, 2014). The invasive species status of L. camara has become the most significant barrier for growers and landscapers who are interested in producing or planting L. camara.

The major determinant of the invasive potential of $L$. camara is its ability to produce viable pollen that can be transferred onto native lantana's flowers by pollinators. Dehgan (2006) indicated the existence of a wide range of pollen stainability (from less than $5 \%$ in Patriot ${ }^{\mathrm{TM}}$ 'Sunburst' to more than $80 \%$ in 'Professor Raoux') in L. camara cultivars in reports to the USDA's Current Research Information System database. However, pollen stainability data for many current lantana cultivars are not available. Other studies on the pollen viability of $L$. camara were mainly based on naturalized populations or wild swarms of lantana plants, where a wide range of pollen viability was observed (Raghavan and Arora, 1960).

The main method used in lantana pollen viability studies has been vital dye-based staining, including aniline stain (Sanders, 1987b; Spies, 1984c) and Alexander's stain (Dehgan, 2006). Brewbaker (1967) showed 


\begin{tabular}{|c|c|c|c|c|c|c|}
\hline \multirow[b]{2}{*}{ Lantana cultivar/breeding lines } & \multirow[b]{2}{*}{$\begin{array}{l}\text { Ploidy } \\
\text { level }\end{array}$} & \multicolumn{2}{|c|}{ Expt. 1} & \multicolumn{2}{|c|}{ Expt. 2} & \multirow[b]{2}{*}{$\begin{array}{l}\text { Avg pollen } \\
\text { stainability }\end{array}$} \\
\hline & & $\begin{array}{l}\text { Pollen } \\
\text { Count }\end{array}$ & $\begin{array}{c}\text { Pollen } \\
\text { stainability }\end{array}$ & $\begin{array}{l}\text { Pollen } \\
\text { Count }\end{array}$ & $\begin{array}{c}\text { Pollen } \\
\text { stainability }\end{array}$ & \\
\hline 'Cream' & $2 x$ & 4441 & $87.1 \pm 1.1$ & 649 & $70.3 \pm 0.3$ & $78.7 \pm 8.4 \mathrm{a}$ \\
\hline 'Denholm White' & $2 x$ & 5116 & $68.3 \pm 1.0$ & 1251 & $72.6 \pm 1.0$ & $70.4 \pm 2.2 \mathrm{abc}$ \\
\hline 'Lola' & $2 x$ & 3492 & $85.6 \pm 1.8$ & 276 & $76.7 \pm 3.3$ & $81.1 \pm 4.4 \mathrm{a}$ \\
\hline LAOP-9 & $2 x$ & 4089 & $88.7 \pm 1.1$ & 304 & $69.3 \pm 17.3$ & $79.0 \pm 9.7 \mathrm{a}$ \\
\hline LAOP-30 & $2 x$ & 5691 & $54.4 \pm 12.3$ & 768 & $74.9 \pm 9.6$ & $64.6 \pm 10.3 \mathrm{abcd}$ \\
\hline 'Athens Rose' & $3 x$ & 5348 & $20.8 \pm 3.1$ & 694 & $20.3 \pm 3.5$ & $20.5 \pm 0.3$ ghij \\
\hline $\begin{array}{l}\text { 'Balandimpea' (Landmark }{ }^{\mathrm{TM}} \\
\text { Peach Sunrise PP19,358) Improved }\end{array}$ & $3 x$ & 4055 & $21.8 \pm 2.8$ & 402 & $32.3 \pm 0.9$ & $27.1 \pm 5.2 \mathrm{fghi}$ \\
\hline $\begin{array}{l}\text { 'Balandpawn' (Landmark }{ }^{\mathrm{TM}} \\
\text { Pink Dawn PP15,516) }\end{array}$ & $3 x$ & 4621 & $8.9 \pm 3.2$ & 731 & $4.0 \pm 0.6$ & $6.4 \pm 2.5 \mathrm{klm}$ \\
\hline 'Lemon Drop' & $3 x$ & 4318 & $5.7 \pm 0.9$ & 800 & $1.7 \pm 0.6$ & $3.7 \pm 2.0 \mathrm{~lm}$ \\
\hline 'Lucky Red Hot' & $3 x$ & 4812 & $19.4 \pm 0.9$ & 373 & $9.3 \pm 3.0$ & $14.4 \pm 5.0 \mathrm{ijk}$ \\
\hline ‘Miss Huff’ & $3 x$ & 6414 & $2.0 \pm 0.2$ & 562 & $1.9 \pm 0.8$ & $1.9 \pm 0.0 \mathrm{~m}$ \\
\hline 'New Gold' & $3 x$ & 6074 & $0.8 \pm 0.1$ & 260 & $2.7 \pm 2.0$ & $1.8 \pm 0.9 \mathrm{~m}$ \\
\hline 'New Red Lantana' & $3 x$ & 5291 & $5.6 \pm 0.8$ & 514 & $7.0 \pm 1.7$ & $6.3 \pm 0.7 \mathrm{klm}$ \\
\hline Patriot $^{\mathrm{TM}}$ 'Firewagon' & $3 x$ & 4512 & $19.3 \pm 1.0$ & 442 & $14.7 \pm 2.5$ & $17.0 \pm 2.3 \mathrm{hij}$ \\
\hline 'Red Butler' & $3 x$ & 4911 & $7.5 \pm 1.8$ & 236 & $4.0 \pm 1.7$ & $5.8 \pm 1.8 \mathrm{klm}$ \\
\hline 'Red Spread Lantana' & $3 x$ & 4588 & $6.2 \pm 0.7$ & 399 & $5.7 \pm 0.3$ & $5.9 \pm 0.3 \mathrm{klm}$ \\
\hline 'Samson Lantana' & $3 x$ & 5208 & $6.4 \pm 0.4$ & 483 & $5.2 \pm 0.7$ & $5.8 \pm 0.6 \mathrm{klm}$ \\
\hline 'Sunset Lantana' & $3 x$ & 6465 & $5.2 \pm 0.7$ & 1078 & $3.1 \pm 1.2$ & $4.2 \pm 1.1 \mathrm{~lm}$ \\
\hline 'Carlos' & $4 x$ & 4102 & $54.5 \pm 1.6$ & 1416 & $44.2 \pm 2.4$ & $49.4 \pm 5.2$ bcde \\
\hline 'Dallas Red' & $4 x$ & 4234 & $34.5 \pm 2.3$ & 374 & $29 \pm 1.0$ & $31.7 \pm 2.8$ efgh \\
\hline 'Gold' & $4 x$ & 4727 & $31.0 \pm 9.6$ & 559 & $21.4 \pm 8.2$ & $26.2 \pm 4.8 \mathrm{fghi}$ \\
\hline 'Irene' & $4 x$ & 3994 & $55.1 \pm 1.2$ & 1272 & $59.7 \pm 3.2$ & $57.4 \pm 2.3 \mathrm{abcd}$ \\
\hline 'Pink Caprice' & $4 x$ & 3227 & $75.9 \pm 2.3$ & 966 & $71.1 \pm 1.9$ & $73.5 \pm 2.4 \mathrm{ab}$ \\
\hline 'Radiation' & $4 x$ & 3961 & $40.7 \pm 11.2$ & 576 & $23.9 \pm 2.7$ & $32.3 \pm 8.4$ efgh \\
\hline 'Cajun Pink' & $5 x$ & 4241 & $41.2 \pm 2.5$ & 229 & $23.4 \pm 2.0$ & $32.3 \pm 8.9 \mathrm{efg}$ \\
\hline Patriot $^{\mathrm{TM}}$ 'Hallelujah' & $5 x$ & 5423 & $41.3 \pm 4.3$ & 938 & $42.5 \pm 3.1$ & $41.9 \pm 0.6 \mathrm{def}$ \\
\hline 'Spreading Sunset' & $5 x$ & 6609 & $13.6 \pm 2.0$ & 2463 & $25.4 \pm 5.5$ & $19.5 \pm 5.9$ ghij \\
\hline $629-1$ & $5 x$ & 3946 & $33.0 \pm 3.1$ & 700 & $29.5 \pm 3.8$ & $31.2 \pm 1.8 \mathrm{efgh}$ \\
\hline $629-2$ & $5 x$ & 3646 & $52.9 \pm 3.0$ & 1287 & $43.7 \pm 5.6$ & $48.3 \pm 4.6 \mathrm{cde}$ \\
\hline 'Tangerine' & $6 x$ & 3881 & $24.5 \pm 5.2$ & 285 & $17.3 \pm 3.0$ & $20.9 \pm 3.6$ ghij \\
\hline $620-10$ & $6 x$ & 6668 & $9.9 \pm 0.9$ & 1237 & $14.0 \pm 4.1$ & $11.9 \pm 2 \mathrm{jkl}$ \\
\hline $621-4$ & $6 x$ & 3389 & $24.5 \pm 2.4$ & 512 & $17.9 \pm 2.7$ & $21.2 \pm 3.3$ ghij \\
\hline L. montevidensis (lavender) & $3 x$ & 3308 & $1.2 \pm 0.0$ & 770 & $0.2 \pm 0.2$ & $0.7 \pm 0.5 \mathrm{~m}$ \\
\hline L. montevidensis (white) & $3 x$ & 5966 & $2.4 \pm 0.3$ & 248 & $0.6 \pm 0.6$ & $1.5 \pm 0.9 \mathrm{~lm}$ \\
\hline
\end{tabular}

${ }^{\mathrm{z}}$ Expt. 1 was conducted in Gainesville, FL, in 2008 and Expt. 2 was conducted in Balm, FL, in 2009.

' ${ }^{y}$ owercase letters indicate statistical groupings with Tukey's $\mathrm{W}$ procedure significance at $P \leq 0.05$.

that lantana pollen grains were binucleate. Attempts to germinate lantana pollen grains on artificial media were unsuccessful (Brewbaker and Kwack, 1963; Khaleel and Nalini, 1972), and the cause(s) of such in vitro germination failures remain to be identified. Thus, pollen stainability has been the primary parameter used in lantana pollen viability assessment.

This study was conducted to determine the ploidy levels and pollen stainability of 32 L. camara cultivars and breeding lines. The main objective was to gain a better understanding of the relationship between ploidy level and pollen stainability in L. camara and to assess the effectiveness of ploidy manipulation for producing sterile L. camara cultivars. A secondary objective was to identify male-sterile cultivars for commercial production and landscape use and examine pollen mother cells and microspores for meiotic abnormities that might lead to low pollen stainability.

\section{Materials and Methods}

Plant materials. Twenty-six commercial L. camara cultivars and six University of Florida (UF) breeding lines were used along with two sterile cultivars of Lantana montividensis (Spreng.) Briq. (Henderson, 1969) included as references (Table 1). Cuttings of 'Cream', 'Pink Caprice', and 'Radiation' were donated by Dr. B. Dehgan (Department of Environmental Horticulture, University of Florida, Gainesville, FL); rooted cuttings of 'New Gold', L. montividensis lavender, and L. montividensis white were donated by Myer's Nursery (Thonotoasssa, FL); cuttings of the remaining cultivars were donated by or purchased from Robrick Nursery (Hawthorne, FL). Lantana plants were grown in plastic containers $(15.2 \mathrm{~cm}$ in diameter) filled with a commercial soilless mix (Fafard 2P mix; Florida Potting Soil, Orlando, FL). Plants were irrigated through drip lines and fertilized by constant feeding with 150 $\mathrm{mg} \cdot \mathrm{L}^{-1}$ of a $20-20-20 \quad(20 \mathrm{~N}-8.8 \mathrm{P}-16.6 \mathrm{~K})$ water-soluble fertilizer (Expt. 1) or by incorporating a controlled-release fertilizer (Osmocote, 15N-3.9P-10K, 5-6 months release at $21{ }^{\circ} \mathrm{C}$; The Scotts Company, Marysville, $\mathrm{OH}$ ) at $6.51 \mathrm{~kg} \cdot \mathrm{m}^{-3}$ (Expt. 2). All plants were grown inside greenhouses under natural light. The day and night temperature inside the greenhouses were set at 29.4 and $21.1^{\circ} \mathrm{C}$.

Ploidy analysis. Ploidy level of each cultivar/UF breeding line was determined using fully expanded young leaves and the
Partec PA I ploidy analyzer, a type of flow cytometer, with the CyStain ultraviolet Ploidy Precise P dye (Partec, Münster, Germany), as described by Czarnecki and Deng (2009). The ploidy levels of sample materials were determined by comparing with one or more of the following four commercial cultivars (references) with known ploidy levels. Previous chromosome counting confirmed that 'Cream' is a diploid $(2 n=2 x=22)$, and 'Gold', 'Pink Caprice', and 'Radiation' are tetraploids ( $2 n=$ $4 x=44)$. For each cultivar/UF breeding line, multiple leaf samples from at least three plants were analyzed for their ploidy levels.

Pollen staining. Two vital stains were used to assess the pollen stainability of $L$. camara, lactophenol cotton blue (CB) (Eng. Scientific, Inc., Clifton, NJ) and fluorescein diacetate (FDA) (Sigma-Aldrich, St. Louis, MO). The commercial CB stain solution contained phenol, glycerol, lactic acid, and aniline blue and was purchased ready for use. Flower clusters (inflorescences) were collected when the clusters each had at least one flower partially open. Pre-dehiscent anthers were removed from unopened flowers and placed in a 1.5 -mL Eppendorf tube with $\approx 100 \mu \mathrm{L}$ of $\mathrm{CB}$ stain. Anthers were stained overnight at $65^{\circ} \mathrm{C}$ in a water bath and then rinsed three times with 
distilled water. Care was taken not to burst anthers while rinsing them. Rinsed anthers were squashed in $50 \mu \mathrm{L}$ of glycerol (diluted with $20 \%$ water) on a glass slide. Pollen grains were observed under a bright field microscope [Leica MZ16F or Olympus BH-2 (Tokyo, Japan)] using a $40 \times$ magnification objective. Photos of pollen grains were taken using an Olympus Q Color 5 (Olympus Corporation of America, Center Valley, PA) or a Kodak Easy Share camera (Eastman Kodak, Rochester, NY) mounted to the microscope. Images of pollen grains were later examined on a computer. Pollen grains stained to dark blue were considered stainable (Fig. 1A).

The protocol of Helslop-Harrison and Helslop-Harrison (1970) was followed with minor modifications for FDA staining of pollen grains. Fresh anthers were collected from unopened flowers and stained overnight in a FDA solution containing $10^{-6} \mathrm{M}$ FDA and $0.25 \mathrm{M}$ sucrose at room temperature $\left(\approx 22{ }^{\circ} \mathrm{C}\right)$ in the dark. Stained anthers were transferred onto a microscope slide and covered with a coverslip. The slide was gently tapped and pressed to release pollen grains out of anthers. Pollen grains were examined using a fluorescence microscope (Olympus BX 41). Uniformly round, non-wrinkled, brightly fluorescing pollen grains were considered viable (Fig. 1B). Non-fluorescing or lightly fluorescing and wrinkled or deformed pollen grains were considered non-viable.

Two experiments were conducted to assess the pollen stainability of $L$. camara: Expt. 1 was performed in Gainesville, FL, in Apr. and May 2008 and Expt. 2 in Wimauma, FL, in Nov. 2009. In Expt. 1, plants were arranged in the greenhouse following a randomized complete block design with four replicates. For each experimental unit, at least 12 anthers from three flower clusters were examined. Two slides were prepared for each experimental unit; three fields on a slide were randomly selected and photographed. All pollen grains in a given field were counted. In Expt. 2, the same experimental design was used, except that there were three replicates per cultivar, and one glass slide was prepared for each experimental unit.

Pollen stainability data were analyzed using PROC GLM in SAS for Windows 9.2 (SAS Institute, Cary, NC) to determine the significance of differences among ploidy levels and lantana cultivars or UF breeding lines or between experiments and vital dyes. Data transformation was performed using the arcsine square root function. When differences for pollen stainability among cultivars/ UF breeding lines or ploidy levels were significant, mean separation analysis was performed using the Tukey's W procedure in SAS.

Meiotic observations. Immature flower clusters, 1 to $20 \mathrm{~mm}$ in size, were collected from greenhouse-grown plants, fixed in a fresh, cold solution of methanol:acetic acid $(3: 1, v / v)$ for at least $24 \mathrm{~h}$, and kept at $-20^{\circ} \mathrm{C}$. Twelve to 15 anthers were removed from each inflorescence and placed on a glass slide. Anthers were squashed in a small drop of modified carbol fuchsin stain (Kao, 1975), anther debris was carefully removed, and a coverslip was placed on the squashed anthers. When pollen mother cells, microspores, or pollen grains were released in the squash, the coverslip was sealed with nail polish and then firmly tapped with a blunt plastic instrument. Prepared slides were observed under an Olympus BH-2 compound microscope. Photos of pollen mother cells undergoing meiosis were taken using an Olympus Oly-750 microscope camera and the computer software Image-Pro ${ }^{\circledR}$ Plus 6.2 (Media Cybernetics, Inc., Rockville, MD). Lantana cultivars examined for meiosis include 'Athens Rose', 'Lola', 'Miss Huff', 'New Gold', and 'Pink Caprice'. Most of the meiotic work was conducted at the University of Georgia (Athens and Griffin, GA).

\section{Results}

Ploidy analysis. A polyploid series was observed among the 26 commercial cultivars and six UF breeding lines analyzed for ploidy level (Table 1). There were 13 triploids, six tetraploids, five pentaploids, and three hexaploid (Table 1).

Dye comparison for lantana pollen staining. Cotton blue and FDA were used in parallel to stain the pollen of eight cultivars representing a wide range of pollen stainability. The two staining methods revealed similar percentages of pollen stainability or viability in these cultivars (Figs. 1 and 2). Statistical analysis indicated that the two staining methods were not significantly different and there was no interaction between staining methods and lantana cultivars/breeding lines [analysis of variance (ANOVA) results not shown]. The pollen stainability by $\mathrm{CB}$ and the viability by FDA were highly positively correlated with an $R^{2}$ of $0.94(P<0.0001)$ (Fig. 2). Thus, for staining lantana pollen, either dye could be equally effective. FDA staining requires the use of a fluorescence microscope; thus, $\mathrm{CB}$ was chosen for assessing lantana pollen stainability.

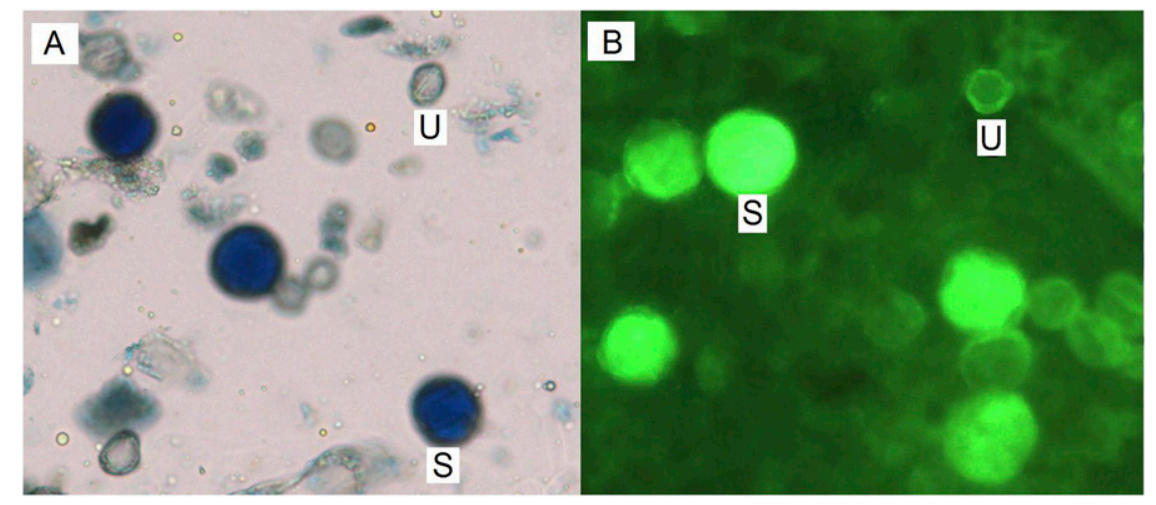

Fig. 1. Stainable (S) and unstainable (U) Lantana pollen grains detected with cotton blue stain under a bright field microscope (A) or fluorescein diacetate stain under a fluorescence microscope (B). Pollen grains were collected from L. camara 'Tangerine'.

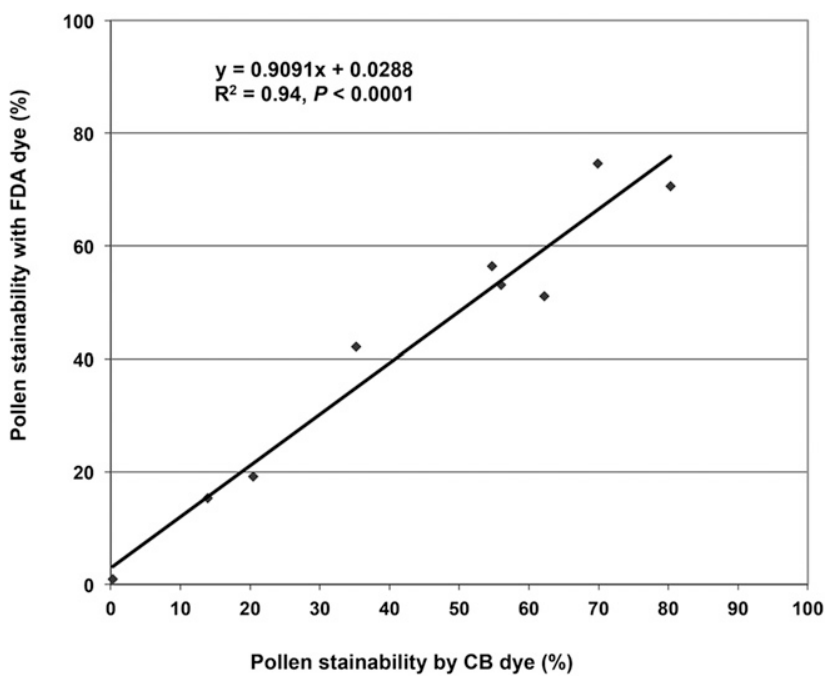

Fig. 2. Linear correlation of pollen stainability (\%) of eight $L$. camara cultivars detected by two vital stains, cotton blue (CB) and fluorescein diacetate (FDA). Pollen stainability of each cultivar revealed by the two stains was not significantly different $(P=0.803)$. 
Pollen stainability of lantana cultivars and UF breeding lines. In Expt. 1, 3227 to 6668 pollen grains were examined per cultivar/breeding line (Table 1). The lowest pollen stainability was $0.8 \%$ ('New Gold') and the highest was $88.7 \%$ (LAOP-9), i.e., a 110-fold difference. In Expt. 2229 to 2463 pollen grains were examined per cultivar/ breeding line. The lowest and highest pollen stainability were $1.7 \%$ ('New Gold') and $76.7 \%$ ('Lola'), respectively, i.e., a 45-fold difference. Significant pollen stainability differences were found among lantana cultivars (Table 1).

Most of the cultivars/UF breeding lines (17) had similar $( \pm 5 \%)$ pollen stainability between the two experiments. However, the pollen stainability of nine cultivars/UF breeding lines ['Cream', LAOP-9, LAOP-30, 'Balandimpea' (Landmark ${ }^{\mathrm{TM}}$ Peach Sunrise PP19,358), 'Lucky Red Hot', 'Carlos', 'Radiation', 'Cajun Pink', and 'Spreading Sunset'] fluctuated between experiments ( \pm $10 \%$ to $\pm 20.5 \%$ ). Additionally, there were six cultivars whose pollen stainability changed by $\pm 5 \%$ to $\pm 10 \%$. These fluctuations resulted in an overall significant difference between the two experiments and significant interactions between cultivar and experiments (ANOVA results not shown). It remains to be known what factors caused the differences between the two experiments in pollen stainability.

When data were pooled by ploidy level, diploids had the highest average pollen stainability $(74.8 \%)$, and triploids had the lowest average pollen stainability $(9.3 \%)$ (Table 2). Pollen stainability of tetraploids was between that of diploids and triploids with an average of $45.1 \%$. Pentaploids had an average pollen stainability of $34.6 \%$, slightly lower than tetraploids, but the difference between them was not statistically significant. Hexaploids had low average pollen stainability $(18.0 \%)$, and it was significantly different from the pollen stainability of other ploidy levels. These results indicate that ploidy level is the most important factor determining the pollen stainability of L. camara.

Diploids. All diploid cultivars and UF breeding lines showed high pollen stainability, ranging from $54.4 \%$ to $88.7 \%$. Pollen stainability of 'Denholm White' and 'Lola' was consistent between experiments $( \pm 4.3 \%$ to $8.9 \%$ ), whereas that of 'Cream', LAOP-9, and LAOP-30 changed more ( $\pm 16.8 \%$ to $20.5 \%$ ). 'Lola' and its two open-pollinated progeny had similar pollen stainability (Table 1).

Table 2. Differences in pollen stainability among ploidy levels of Lantana.

\begin{tabular}{lccccccc}
\hline Species & $\begin{array}{c}\text { Ploidy } \\
\text { level }\end{array}$ & $\begin{array}{c}\text { Lines } \\
\text { sampled }\end{array}$ & $\begin{array}{c}\text { Pollen } \\
\text { counted }\end{array}$ & $\begin{array}{c}\text { Lowest } \\
\text { stainability }\end{array}$ & $\begin{array}{c}\text { Highest } \\
\text { stainability }\end{array}$ & $\begin{array}{c}\text { Avg pollen } \\
\text { stainability }(\%)^{\mathrm{z}}\end{array}$ & SE \\
\hline L. camara & $2 x$ & 6 & 26077 & 64.6 & 81.1 & $64.6 \mathrm{a}$ & 3.1 \\
& $3 x$ & 13 & 73591 & 1.8 & 27.1 & $9.3 \mathrm{~d}$ & 2.2 \\
& $4 x$ & 6 & 29408 & 26.2 & 73.5 & $45.1 \mathrm{~b}$ & 7.5 \\
& $5 x$ & 5 & 29482 & 19.5 & 48.3 & $34.6 \mathrm{~b}$ & 4.9 \\
& $6 x$ & 3 & 15972 & 11.9 & 21.2 & $18.0 \mathrm{c}$ & 3.1 \\
L. montevidensis & $3 x$ & 2 & 10292 & 0.7 & 1.5 & $1.1 \mathrm{e}$ & 0.4 \\
\hline
\end{tabular}

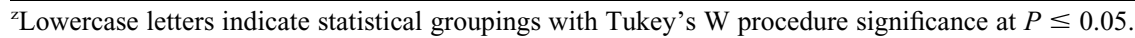

Triploids. Based on the average pollen stainability over two experiments, lantana triploids could be divided into four groups. The first group had pollen stainability below $5 \%$, which includes four cultivars, Lemon Drop, Miss Huff, New Gold, and Sunset Lantana. 'New Gold' and 'Miss Huff' had the lowest pollen stainability, $1.8 \%$ to $1.9 \%$, and their pollen stainability changed minimally $( \pm 0.1$ to 4.9 in percentage) between the two experiments. The second group consisted of cultivars with pollen stainability between $5 \%$ and $10 \%$, including five cultivars, Balandpawn, New Red Lantana, Red Butler, Red Spread Lantana, and Samson Lantana. The third group had pollen stainability between $10 \%$ and $20 \%$ and consisted of two cultivars, Lucky Red Hot and Patriot ${ }^{\mathrm{TM}}$ Firewagon. Another two cultivars (Athens Rose and Balandimpea) constituted the fourth group, whose pollen stainability was between $20 \%$ and $30 \%$. Overall larger variation was observed in Groups 3 and 4 (4.6\% to $10.5 \%)$ than in Group 1 cultivars $(0.1 \%$ to $4.9 \%)$.

Tetraploids. Three cultivars, Gold, Dallas Red, and Radiation, had similar pollen stainability ( $26.2 \%$ to $32.3 \%$ ), but overall, a large range of variation in pollen stainability was present among lantana tetraploids. 'Irene' and 'Pink Caprice' had an average of 57.4\% and $73.5 \%$ pollen stainability, respectively, statistically similar to that of the diploids. The average pollen stainability of 'Carlos' was $49.4 \%$, significantly different from diploids 'Cream' and 'Lola' but not significantly different from diploid 'Denholm White'.

Pentaploids and hexaploids. Except for one cultivar (Spreading Sunset), pentaploid cultivars had average pollen stainability $(32.3 \%$ in 'Cajun Pink' to $48.3 \%$ in UF breeding line 629-2), similar to that of most tetraploids. The average pollen stainability of 'Spreading Sunset' was $19.5 \%$, similar to that of hexaploids and some triploids (Group 3).

'Tangerine' was the only hexaploid cultivar, and its average pollen stainability was $20.9 \%$, similar to that of Group 3 or 4 triploids. Two hexaploid UF breeding lines had similar pollen stainability $(11.9 \%$ to $21.2 \%)$.

Meiotic abnormalities. Five cultivars, Lola (diploid with high pollen stainability), Pink Caprice (tetraploid with high pollen stainability), Miss Muffet and New Gold (triploids with extremely low pollen stainability), and Athens Rose (triploid with higher pollen stainability) were chosen for meiotic observations. Flower clusters ranging from $0.5 \mathrm{~mm}$ to $15 \mathrm{~mm}$ in size were examined to identify the best stage for meiotic analysis. Fully developed pollen was found in all flower sizes examined, which indicates that meiosis occurred very early in lantana flower development. Most of the meiotic products in the diploid cultivar Lola and tetraploid cultivar Pink Caprice were normal, although some abnormalities were seen. More types of abnormalities were observed in the anthers of triploid cultivars Miss Huff, New Gold, and Athens Rose. Observed abnormalities included lagging chromosomes, fused tetrads, pentads, hexads, and variable-sized pollen grains (Fig. 3).

\section{Discussion}

Of the 26 commercial L. camara cultivars analyzed for ploidy levels, half of them were triploids, whereas diploids and tetraploids were less common. This ploidy level distribution was quite different from what were reported previously about the ploidy level of wild swarm lantana collections (Spies, 1984b), where tetraploids were the most common. This change likely reflects an increased effort by commercial and private lantana breeders toward selecting less fertile lantana cultivars over the past three decades. Among the five ploidy levels in L. camara, triploids exhibited average pollen stainability below $10 \%$, which is $\approx 15 \%$ of diploids' average pollen stainability and $20 \%$ of tetraploids' average pollen stainability. The remarkable reduction of pollen stainability in triploids suggests an excellent potential for developing sterile, non-invasive $L$. camara cultivars through triploid creation and selection. Several of the commercial triploid cultivars (Balandpawn, Lemon Drop, Lucky Red Hot, Miss Muffet, New Gold, New Red Lantana, Red Butler, Red Spread Lantana, Samson Lantana, and Sunset Lantana) showed high levels of male sterility and had pollen stainability below $10 \%$. They are good candidates for further testing of female sterility and hybridization potential with L. depressa. Triploid cultivars with high levels of male and female sterility and little hybridization potential with $L$. depressa will be highly desirable for commercial production and landscape use to minimize potential negative impacts of $L$. camara to native species and the environment.

Compared with the large differences in pollen stainability among commercial lantana cultivars, Khoshoo and Mahal (1967) and Raghavan and Arora (1960) reported much smaller differences in pollen stainability among naturalized L. camara diploids ( $48 \%$ to $90 \%$ ), triploids $(16 \%$ to $47 \%$ ), and tetraploids ( $16 \%$ to $91 \%$ ). Possibly, highly sterile lantana individuals might have been eliminated in the naturalized populations during natural selection because of their low pollen stainability or viability.

A number of chromosome paring arrangements such as univalents, trivalents, and quadravalents could lead to meiotic abnormalities and pollen abortion in lantana (Spies 1984a). Spies and Stirton (1982) observed 


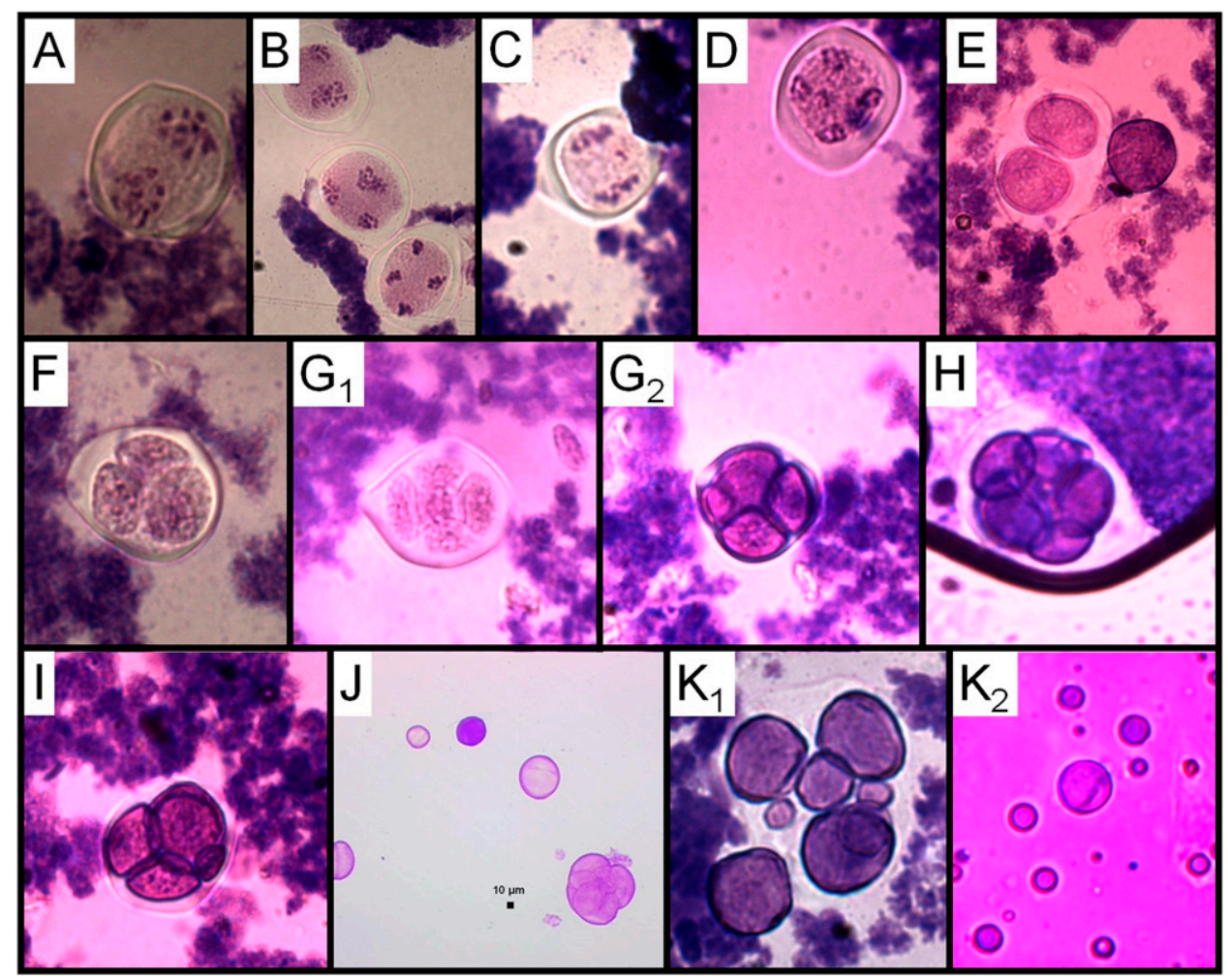

Fig. 3. Normal meiosis and abnormalities observed in L. camara pollen mother cells, microspores, and pollen grains. (A) Normal Anaphase I ('Lola'), (B) normal Telophase II ('Lola'), (C) lagging chromosome in Telophase I ('Lola'), (D) lagging chromosome in Telophase II ('Miss Huff'), (E) dyad ('Pink Caprice'), (F) triad formation ('Lola') $\left(\mathrm{G}_{1}\right.$ and $\left.\mathrm{G}_{2}\right)$ Pentad formation, $(\mathbf{H})$ hexad formation ('New Gold'), (I) tetrad with uneven different sized microspores ('Pink Caprice'), (J) fused tetrads after tetrad sac rupture ('Miss Huff'), and (K) variable-sized pollen grains ( $\mathrm{K}_{1}$ in 'Athens Rose' and $\mathrm{K}_{2}$ in 'Miss Huff').

a strong correlation between normal bivalent chromosome pairing and high levels of pollen viability in $L$. camara diploids and triploids and a moderate level of negative correlation between trivalents and pollen viability in L. camara tetraploids. The meiotic abnormalities observed in these commercial L. camara cultivars (lagging chromosomes, abnormal telophase divisions, uneven tetrads, polyads, etc.) likely resulted from univalent, trivalent, and/or quadrivalent formation in lantana pollen mother cells.

Significant pollen stainability variation was observed among L. camara cultivars/UF breeding lines of the same ploidy level in tetraploids, pentaploids, and triploids (Table 2 ). This variation may suggest that other genetic factors may also play a significant role in determining the pollen stainability or male fertility of L. camara. Raghavan and Arora (1960) observed high male sterility in a $L$. camara diploid and suspected possible male sterility gene(s) in Lantana. The pollen stainability of a number of cultivars varied significantly between experiments, indicating strong influences of environmental conditions on $L$. camara pollen stainability in at least some cultivars. Seasonal pollen stainability variation was observed previously (Dehgan, 2006). Therefore, it is important to examine L. camara pollen stainability over at least two seasons or two sites.

A number of ornamental plants in the United States are like L. camara, having tremendous value to the U.S. nursery and landscape industry yet but posing considerable invasive potential that could cause significant ecological and economic damage. Evaluation of male and/or female fertility will be essential for developing and introducing sterile non-invasive cultivars in these plants (Vining et al., 2012). Substantial efforts are being made by a number of university and governmental research programs in this important area (Anderson et al., 2004; Czarnecki et al., 2012; Freyre et al., 2013; Knox and Wilson, 2006; Ranney, 2004; Trueblood et al., 2010; Wilson and Mecca, 2003). These efforts, including the present study, will make significant contributions to the long-term sustainability and profitability of the nursery and landscape industry and to the protection of the environment and native species. Results from these studies are also useful in helping environmental scientists have a better understanding of the reproductive biology of invasive plants.

\section{Literature Cited}

Anderson, N.O., S.M. Galatowitsch, and N. Gomez. 2004. Selection strategies to reduce invasive potential in introduced plants. Euphytica 148:203-216.

Arnold, M.A. 2002. Landscape plants for Texas and Environs. Stipes Publishing, Champaign, IL.

Brewbaker, J.L. 1967. The distribution and phylogenetic significance of binucleate and trinucleate pollen grains in the angiosperms. J. Bot. 54:1069-1083.
Brewbaker, J.L. and B.H. Kwack. 1963. The essential role of calcium ion in pollen germination and pollen tube growth. Amer. J. Bot. 50:859-865.

Czarnecki, D.M., II, and Z. Deng. 2009. Occurrence of unreduced female gametes leads to sexual polyploidization in Lantana. J. Amer. Soc. Hort. Sci. 134:560-566.

Czarnecki, D.M., II, S.B. Wilson, G.W. Knox, R. Freyre, and Z. Deng. 2012. UF-T3 and UFT4: Two sterile Lantana camara cultivars. HortScience 47:132-137.

Dehgan, B. 2006. Reproductive biology and invasive potential of Lantana camara cultivars. U.S. Department of Agriculture Research, Education \& Economics. Inf. Syst. 15 July 2014. <http://www.reeis.usda.gov/ web/crisprojectpages/0191420-reproductivebiology-and-invasive-potential-of-lantanacamara-cultivars.html $>$.

Florida Exotic Pest Plant Council. 2001. Florida Exotic Pest Plant Council's 2001 list of invasive species. 18 July 2014. <http://www.fleppc.org/ list/list.htm>.

Freyre, R., A. Moseley, C. Reinhardt-Adams, A.G.W. Knox, S.B. Wilson, and Z. Deng. 2013. Breeding Ruellia spp. at the University of Florida. Acta Hort. 1000:423-428.

Hammer, R.L. 2004. The Lantana mess: A critical look at the genus in Florida. The Palmetto. 23:21-23.

Helslop-Harrison, J. and Y. Helslop-Harrison. 1970. Evaluation of pollen viability by enzymatically induced fluorescence: Intracellular hydrolysis of fluorescein diacetate. Stain Technol. 45:115120 .

Henderson, R.J.F. 1969. A cytological study of Lantana montevidensis (Spreng) Briq. in 
Queensland. Contributions from the Queensland Herbarium (Issue 3). Reid., Brisbane, Australia.

Howard, R. 1969. A check list of cultivar names used in the genus Lantana. Arnoldia 29:73-109.

IFAS Invasive Plant Working Group. 2014. IFAS Assessment of non-native plants in Florida's natural areas. 18 July 2014. <http://plants.ifas.ufl.edu/assessment>.

Kao, K.N. 1975. A nuclear staining method for plant protoplasts, p. 60-62. In: Gamborg, O.L. and L.R. Wetter (eds.). Plant tissue culture methods. National Research Council of Canada, Saskatoon, Canada.

Khaleel, T.F. and A.S. Nalini. 1972. Embryology of Lantana aculeata Linn. var. nivea Bailey. Current Sci. (India) 41:491-494.

Khoshoo, T.N. and C. Mahal. 1967. Versatile reproduction in Lantana camara. Current Science Bangalore 36:201-203.

Knox, G.W. and S.B. Wilson. 2006. Evaluating north and south Florida landscape performance and fruiting of ten cultivars and a wild-type selection of Nandina domestica, a potentially invasive shrub. J. Environ. Hort. 24:137-142.

Mathur, G. and H.Y. Ram. 1986. Floral biology and pollination of Lantana camara. Phytomorphology 36:79-100.

Raghavan, R.S. and C.M. Arora. 1960. Morphological and cytological studies in the genus Lantana L. Bull. Bot. Surv. India. 2:299-303.
Ranney, T.G. 2004. Population control: Developing non-invasive nursery crops. Combined Proc. Intl. Plant Propagators' Soc. 54:604-607.

Sanders, R.W. 1987a. Identity of Lantana depressa and L. ovatifolia (Verbenaceae) of Florida and the Bahamas. Syst. Bot. 12:44-60.

Sanders, R.W. 1987b. A new species of Lantana (Verbenaceae) from Dominica, Lesser Antilles. J. Arnold Arbor. 68:343-348.

Sanders, R.W. 2001. The genera of Verbenaceae in the southeastern United States. Harv. Pap. Bot. 5:303-358.

Sanders, R.W. 2006. Taxonomy of Lantana sect. Lantana (Verbenaceae): I. Correct application of Lantana camara and associated names. Sida 22:381-421.

Schemske, D.W. 1976. Pollinator specificity in Lantana camara and L. trifolia (Verbenaceae). Biotropica 8:260-264.

Schoellhorn, R. 2004. Lantana-Summer color that's tough as nails. GPN-Greenhouse Product News 14:14-16.

Spies, J.J. 1984a. A cytotaxonomic study of Lantana camara (Verbenaceae) from South Africa. S. Afr. J. Bot. 3:231-250.

Spies, J.J. 1984b. Embryo sac development in some South African cultivars of Lantana camara. Bothalia 15:161-166.

Spies, J.J. 1984c. Hybridization potential of Lantana camara (Verbenaceae). Garcia de Orta Series Biol 6:145-150.
Spies, J.J. and C.H. Stirton. 1982. Meiotic studies of some South African cultivars of Lantana camara (Verbenaceae). Bothalia 14:101111.

Trueblood, C.E., T.G. Ranney, N.P. Lynch, J.C. Neal, and R.T. Olsen. 2010. Evaluating fertility in triploid clones of Hypericum androsaemum L. for use as non-invasive landscape plants. HortScience 45:1026-1028.

U.S. Department of Agriculture/Natural Resources Conservation Service. 2011. Plant database. 24 Jan. 2011. <http://plants.usda.gov/java/ profile?symbol=LANTA $>$.

Vining, K.J., R.N. Contreras, M. Ranik, and S.H. Strauss. 2012. Genetic methods for mitigating invasiveness of woody ornamental plants: Research needs and opportunities. HortScience 47:1210-1216.

Weaver, R.E. and P.J. Anderson. 2010. Notes on Florida's endangered and threatened plants. 15 July 2014. <http://freshfromflorida.s3.amazonaws. com/fl-endangered-plants.pdf $>$.

Wilson, S.B. and L.A. Mecca. 2003. Seed production and germination of eight cultivars and the wild type of Ruellia tweediana: A potentially invasive ornamental. J. Environ. Hort. 21:137-143.

Wirth, F.F., K.J. Davis, and S.B. Wilson. 2004 Florida nursery sales and economic impacts of 14 potentially invasive ornamental plant species. J. Env. Hort. 22:12-16. 